\title{
Medication Use by Runners in Self-Care Situations
}

\author{
David A. Taylor, Catherine D. Santanello* \\ School of Pharmacy, Southern Illinois University Edwardsville, Edwardsville, IL, USA \\ Email:*csantan@siue.edu
}

How to cite this paper: Taylor, D.A. and Santanello, C.D. (2017) Medication Use by Runners in Self-Care Situations. Pharmacology \& Pharmacy, 8, 263-274.

https://doi.org/10.4236/pp.2017.88019

Received: June 21, 2017

Accepted: August 11, 2017

Published: August 14, 2017

Copyright $\odot 2017$ by authors and Scientific Research Publishing Inc. This work is licensed under the Creative Commons Attribution International License (CC BY 4.0).

http://creativecommons.org/licenses/by/4.0/

\begin{abstract}
The benefits of running for cardiovascular health have long been established, but no relationship between runners/non-runners and their usage of prescription and over-the-counter (OTC) medications has been established. A comprehensive survey was sent out via Facebook, Inc., to self-identified runners to assess runners' first response to 5 common self-care situations. The results were compared to the national average of the U.S. population who take prescription and OTC medications. What was also assessed was the relationship between average weekly miles run and the likelihood to choose OTC medications. 714 runners, residing predominately in the St. Louis, Missouri metropolitan area, completed the survey and their results were drastically different than the national average use for prescription and OTC medication in the general (non-runners) population. Approximately $30 \%$ of the runners in this study are on daily prescription medications versus a national average of $70 \%$ of the U.S. population. In each of the 5 common self-care situations, less than $50 \%$ of runners chose an OTC medication as their first option for self-care vs. the national average of $80 \%$. Results of the study also showed that runners with a weekly mile average of 30 miles or more were less likely to choose an OTC option for self-care than runners with a weekly average of 15 miles or less. Overall, results of this survey suggest that runners are less likely to take medications and may be healthier than the average U.S. citizen overall.
\end{abstract}

\section{Keywords}

Runners, Over-the Counter Medications, Prescription Medications, Health, Self-Care

\section{Introduction}

Over-the-counter (OTC) medications are a first-line treatment for many people in the United States with minor ailments. It is estimated that the average U.S. 
citizen makes 26 trips to a pharmacy to purchase OTC products and spends $\$ 338$ on those products annually [1]. Effective use of OTC products for minor health ailments can prevent unnecessary trips to the doctor's office or to the emergency department. It is estimated that for every dollar spent on OTC medications, the U.S. healthcare system saves 6 to 7 dollars [1]. Taxpayers could save $\$ 5.2$ billion annually if half of unnecessary emergency department visits were avoided by people using more self-care options, including responsible OTC medication use.

The recommended amount of physical activity for adults 18 - 64 years of age is 150 minutes of moderate intensity exercise a week [2]. With respect to vigorous intensity activities, such as running, a total of 75 minutes weekly is recommended. Additional benefits are seen by extending the length of activity to 150 minutes or longer. For a person who runs at a ten-minutes-per-mile pace, this would mean an average of 15 miles per week is needed. To note, health benefits are seen when the 150 minutes of activity are spread over a minimum of 3 days and trying to avoid a long stretch of inactive days [2]. Regular running can slow the effects of aging. According to researchers at the Stanford University School of Medicine, elderly runners have fewer disabilities and are half as likely to die early deaths as non runners [3].

Running is one of the most popular sports in the U.S. In a Running USA study, it was reported that in 2015 there were 17.1 million people who participated in and finished a race [4]. The most common distance (45\%) was a $5 \mathrm{~K}$, then the half-marathon (12\%), with the least popular (3\%) being a marathon. Running has many positive health benefits, but comes with its own risk of injury and other minor self-care needs.

A 2009 survey done by the Mayo Clinic illustrated that almost 70\% of residents in Olmstead County, Minnesota, took at least one prescription medication during that year with $50 \%$ taking a prescription medication in the previous month [5]. In the same study, roughly half of those surveyed took medications from 2 or more drug groups and $20 \%$ took medications from 5 or more drug groups. Their study yielded results similar to other larger population studies on the usage of prescription medications in the U.S. [5]. Over-the-counter medications are also frequently used by many U.S. citizens. In a National Survey of Consumers and Health Professionals done by the National Council on Patient Information and Education, 59\% of Americans reported having taken at least on OTC product in the previous six months [6]. Fifty-four percent of those surveyed reported taking an OTC versus a prescription medication during the previous six months [6].

Because of the investigators' interest in running, the purported health benefits of running, and the potential savings to the health care system by proper OTC medication use, a survey was created to assess the OTC usage habits of runners. In this study, the overall health of runners was assessed by the lack of daily prescription drug usage. It was hypothesized that runners would be less likely to use OTC and/or prescription medications than that of the national average U.S. cit- 
izen. It was also hypothesized that runners with a higher weekly average were less likely to use prescription medications or OTC medications than runners averaging less than 15 miles per week.

\section{Methods}

A survey (Appendix 1) was created using Qualtrics software available with a site license with Southern Illinois University Edwardsville (SIUE). On December 7, 2016, the SIUE Institutional Review Board designated the protocol as exempt from further review and of minimal risk to participants (IRB\#16-1207-100C). A shareable link was generated using the Qualtrics software and was posted on the personal Facebook page of the primary investigator on January 4, 2017. The link was then re-distributed by other Facebook members on their personal pages and in various running groups so it could reach a more diverse population. The survey was voluntary and anonymous and was intended for all people 18 years-ofage and older who self-identify as runners. All participants had the option to withdraw from the survey at any time by closing the survey. No survey participant received any compensation for their time and was able to stop taking the survey at any point.

The survey composed of demographic questions and OTC medication usage questions. In each OTC medication usage question, a common self-care situation was presented that an average runner could encounter. Each situation had a choice of a non-pharmacological self-care option, a homeopathic option, an OTC option, and an exercise/minimal intervention option. All questions required the participant to pick the option that best fit their response to the presented situation. Runners were also asked to pick their OTC pain medication of choice and to indicate if they had ever visited any medical specialist or alternative medical practice for issues related to running. Demographic information is included in Table 1.

The primary intent of this project was to ascertain the percentage of runners that chose OTC medications over other self-care options. Secondary objectives were to determine the usage of prescription or OTC medications by runners running more and less than an average of 15 miles weekly.

\section{Results}

During the open survey period, 754 respondents at least partially participated in the survey and 714 continued to completion. $81 \%$ of runners participating in the survey were women and the most common age group was 41 to 45 years-old. $36.3 \%$ of runners had a Bachelor's degree and $71.2 \%$ of runners had a Bachelor's degree and higher. Only $29.9 \%$ of runners stated that they took daily prescription medications for chronic conditions like asthma, diabetes, high blood pressure, etc.; however, $52.4 \%$ of runners stated they took OTC medications before a run. No statistical analyses were run on the data as it was not appropriate for the data collected. 
Table 1. Demographic information.

\begin{tabular}{|c|c|c|}
\hline & $\mathrm{N}$ & $\%$ \\
\hline \multicolumn{3}{|l|}{ Age } \\
\hline $18-25$ & 26 & 3.5 \\
\hline $26-30$ & 61 & 8.3 \\
\hline $31-35$ & 94 & 12.8 \\
\hline $36-40$ & 122 & 16.6 \\
\hline $41-45$ & 132 & 17.9 \\
\hline $46-50$ & 107 & 14.5 \\
\hline $51-55$ & 87 & 11.8 \\
\hline $56-60$ & 54 & 7.3 \\
\hline $61-65$ & 38 & 5.2 \\
\hline $65+$ & 15 & 2.0 \\
\hline \multicolumn{3}{|l|}{ Gender } \\
\hline Male & 137 & 18.6 \\
\hline Female & 595 & 80.8 \\
\hline Prefer not to answer & 4 & 0.5 \\
\hline \multicolumn{3}{|l|}{ Education } \\
\hline Did not complete HS & 3 & 0.4 \\
\hline High School/GED & 24 & 3.3 \\
\hline Some college & 105 & 14.3 \\
\hline Associate's Degree/Trade School & 79 & 10.8 \\
\hline Bachelor's Degree & 266 & 36.3 \\
\hline Master's Degree & 165 & 22.5 \\
\hline Advanced graduate degree or $\mathrm{PhD}$ & 91 & 12.4 \\
\hline \multicolumn{3}{|l|}{ Miles per week average } \\
\hline $0-5$ & 75 & 10.3 \\
\hline $6-10$ & 104 & 14.3 \\
\hline $11-15$ & 131 & 18.0 \\
\hline $16-20$ & 133 & 18.2 \\
\hline $21-25$ & 91 & 12.5 \\
\hline $26-30$ & 75 & 10.3 \\
\hline $31-35$ & 45 & 6.2 \\
\hline $36-40$ & 27 & 3.7 \\
\hline $40+$ & 49 & 6.7 \\
\hline \multicolumn{3}{|l|}{ Daily prescription meds } \\
\hline Yes & 218 & 29.9 \\
\hline No & 512 & 70.1 \\
\hline \multicolumn{3}{|l|}{ OTC before run } \\
\hline Yes & 382 & 52.4 \\
\hline No & 347 & 47.6 \\
\hline
\end{tabular}


Figures 1-5 show the results for each of the self-care situation questions. When participants of the survey had a headache that lasted at least 20 minutes (Figure 1), 48.7\% chose an OTC medication to help relieve their symptoms. When awakened at night by heartburn (Figure 2) they chose to take an OTC medication $30.6 \%$ of the time. Runners experiencing muscle pain after a long run (Figure 3) only chose an OTC medication $9.4 \%$ of the time versus choosing massaging or stretching the muscles $(78 \%)$. When survey participants were asked which OTC medication they preferred (Figure 4), 83 chose Non-steroidal Anti-inflammatory Drugs (NSAIDS), with ibuprofen being the most common. Less than $3 \%$ chose aspirin and $14 \%$ chose acetaminophen.

The use of herbal supplements or vitamins was the least common choice picked by runners in almost every self-care scenario. The homeopathic option was only chosen around $3 \%$ of the time, but nearly $15 \%$ of runners chose vitamins or herbal supplements to aid with an upper respiratory infection such as a cold.

When prescription medication use was analyzed against average miles run, a small decrease in use was found as average miles increased. $31.6 \%$ of runners who ran less than 15 average miles a week stated they used daily prescription medications versus $27.3 \%$ who ran $30+$ miles weekly.

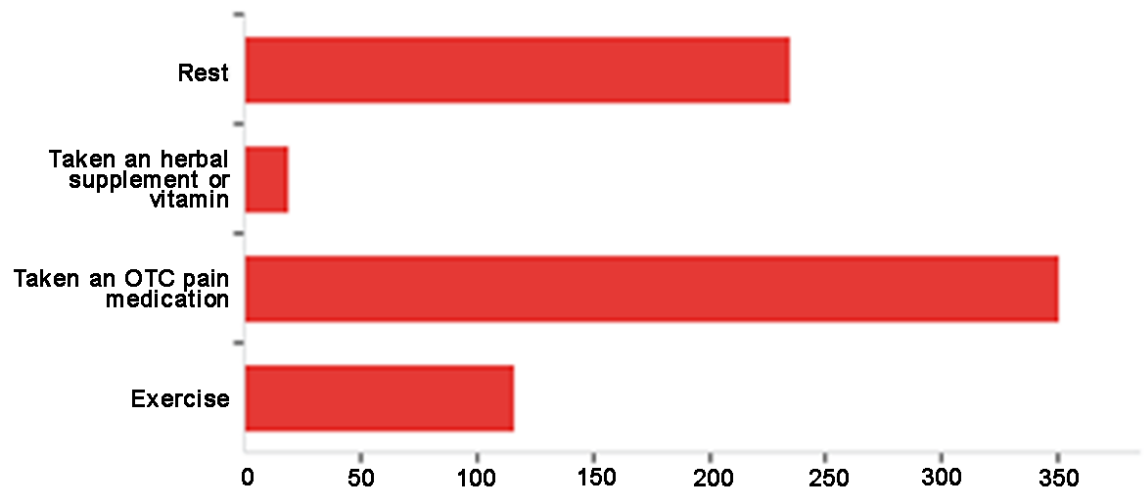

Figure 1. Relief of headaches.

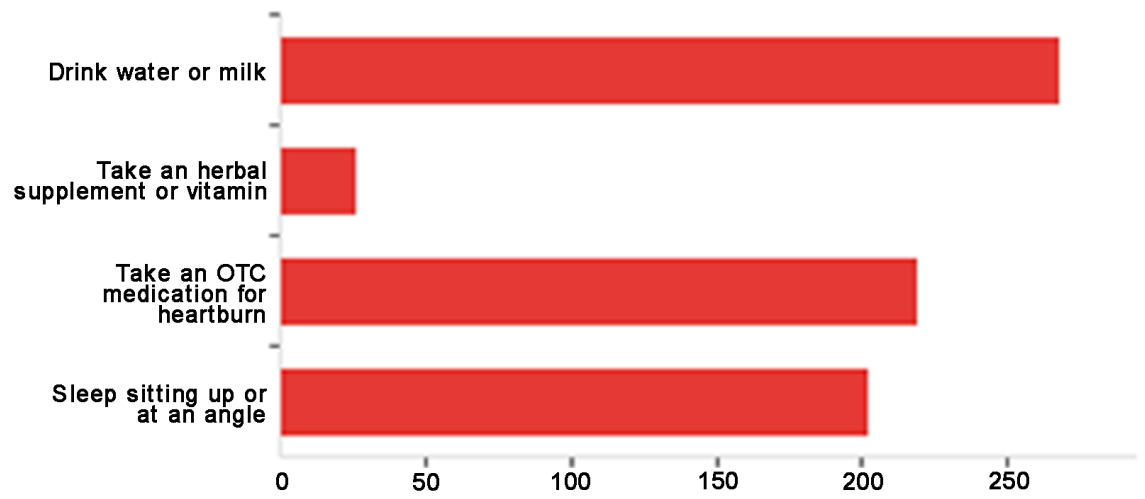

Figure 2. Relief of heartburn. 


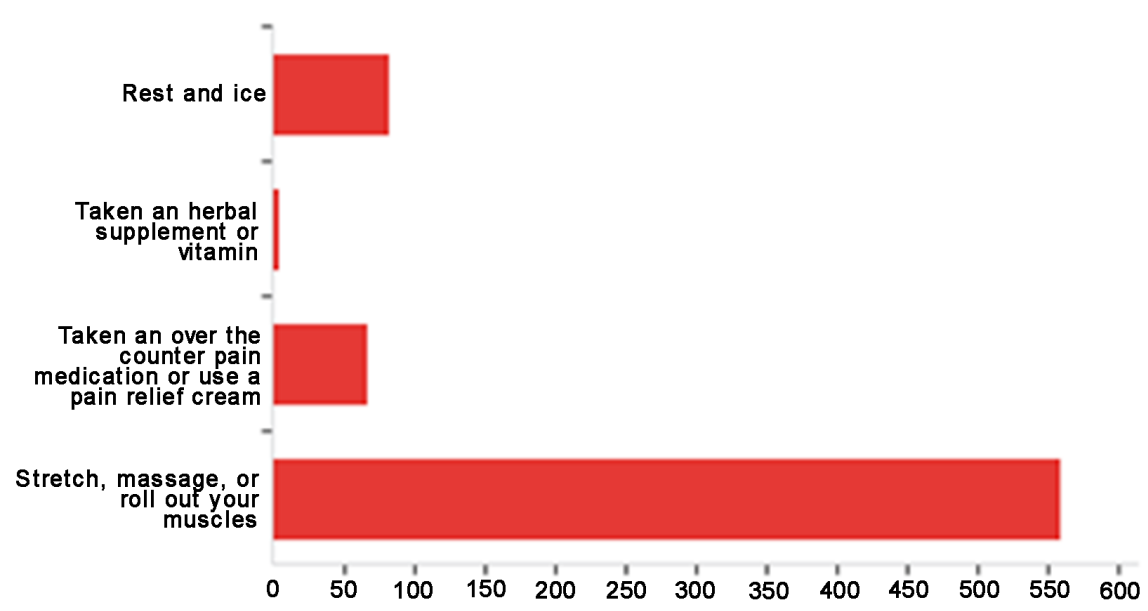

Figure 3. Relief of muscle pain.

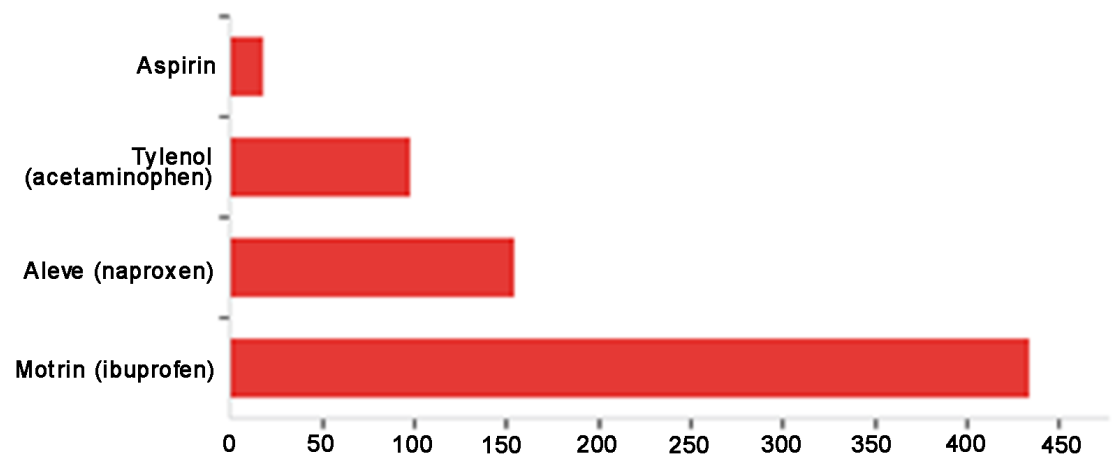

Figure 4. OTC medication preferred.

For the secondary objective, when the weekly average miles ran was compared to the runner's response to Question 2 of the survey regarding relief of headaches, analysis of the results showed a lower percent of runners with 30 or more miles per week average (32.5\%) choose an OTC in comparison to runners with a weekly mile average less than 15 miles weekly (54\%) (Figure 5). Question 2 was chosen for comparison due to the highest number of runners who chose an OTC for this question. The results were similar when weekly mile average was compared to response for each of the 5 self-care questions.

\section{Discussion}

Running is one of the favorite sports enjoyed by millions of people in the U.S. Not only does it have cardiovascular benefits, but it can help improve mood and quality of life. Though injuries requiring medical attention occur, this survey shows that many runners take less prescription medications and OTC medications when compared to the average U.S. citizen. This healthier lifestyle can result in lower personal health care costs and less costs to national health care.

It was hypothesized that runners would use less prescription medications and OTC medications than the average U.S. citizen. Some common illnesses 


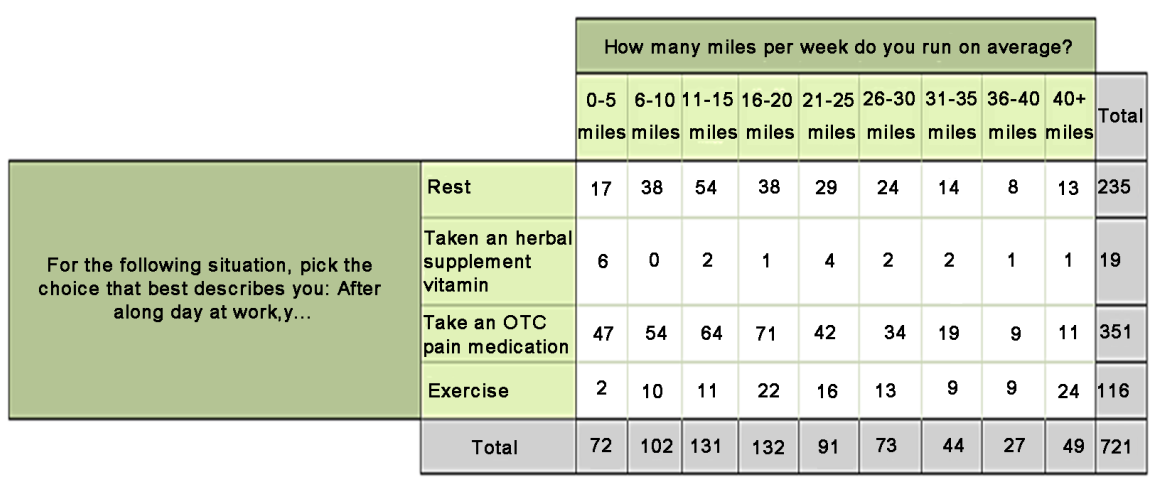

Figure 5. Weekly average miles regarding relief of pain.

requiring daily medications can be due to poor diet, exercise, or lifestyle choices. Getting adequate exercise weekly and eating healthy can lower one's risk factors for diseases like Type 2 diabetes, high blood pressure, high cholesterol, and depression. It is important to note that genetic factors, birth defects, or unmodifiable risk factors can lead to a person getting a disease that needs treatment with prescription medications. Many runners who live healthy lives may require daily prescription medications, so the relationship between prescription medication usage and health may be an oversimplification.

Many runners who took this survey did not represent "all" of the U.S. population. Most of the runners were women with a Bachelor's degree or higher. People with higher levels of education may have higher paying jobs and higher health literacy than people with lower levels of education. This opportunity may equip those individuals with the knowledge and means to choose healthier food options, engage in more physical activity requiring expensive equipment, and have access to information or professionals to aid in their health care decisions.

In addition to the highly educated runners surveyed, race was not asked in the demographic information. Some races and cultures have different philosophies on health care and medication and may be more likely than others to choose homeopathic medicines or home remedies over OTC products for self-care issues. They may also choose activities other than running as an exercise option that is more fitting as a cultural norm.

Another confounder to this survey was the amount of runners who average more than 15 miles weekly. The principal investigator has connections on social media to many ultra-marathoners, people who run races longer than a marathon. Over $50 \%$ of runners who took this survey ran greater than 15 miles weekly, though only $12 \%$ of race finishers ran a half-marathon (13.1 miles) in 2015. It is unlikely that the $45 \%$ of race finishers who ran a $5 \mathrm{~K}$ ( 3.1 miles) were exceeding 15 miles weekly. Though this survey captured a large number of runners who run long distances, the results cannot likely be extrapolated to the average U.S. runner. In addition, the correlation between exercise time, intensity and frequency need to be further assessed. 
Perhaps the most intriguing outcome of the survey data was the amount of runners who use OTC medications prior to a run. $52.4 \%$ of runners stated they have used an OTC medication before initiating a run. Though the reason for use and the specific medication was not determined, the percentage was higher than any of the self-care situations. Common situations for use of OTC medications before a run might be an NSAID use in the anticipation of pain/swelling or loperamide (Imodium) to prevent an unwanted bowel movement during a run. Also, the question was phrased as "have you ever" rather than "have you recently" and could have skewed the numbers higher than the true percentage.

As previously stated, when survey participants were asked which OTC medication they preferred, $83 \%$ of runners chose NSAIDS, with ibuprofen being the most common. According to the National Council on Patient Information and Education, 36\% of Americans admit to combining nonprescription medicines such as NSAIDs when they have multiple symptoms such as headache and muscle pain [6]. Since different OTCs may contain the same active ingredient leading to inappropriate use of OTCs, the use of these OTCs amongst runners and the general population is always a potential concern.

\section{Conclusion}

While this study did have its limitations, it confirms the suggested benefits of running. Many runners in this survey exceeded the recommended amount of weekly physical activity. In addition to getting enough exercise, runners in this study likely had healthier diets and higher health literacy than many U.S. citizens. Overall, runners in this survey took less prescription and OTC medications than the average U.S. citizen. This could result in lower healthcare costs and less dependence on medications, which could contribute to a higher quality of life.

\section{Conflict of Interest}

The authors declare that there is no conflict of interest with this research article.

\section{References}

[1] Statistics on OTC Use. Washington DC: Consumer Healthcare Products Association; c2017. http://www.chpa.org/MarketStats.aspx

[2] Physical Activity Guidelines. Washington DC: U.S. Department of Health and Human Services; c2008.

https://health.gov/paguidelines/guidelines/summary.aspx

[3] Running Slows the Aging Clock. Stanford, CA: Stanford Medicine; c2008. https://med.stanford.edu/news/all-news/2008/08/running-slows-the-aging-clock-sta nford-researchers-find.html

[4] Statistics and Research. Wichita, KS: Running USA; c2017. http://www.runningusa.org/2017-us-road-race-trends

[5] Zhong, W., Maradit-Kremers, H., St. Sauver, J.L., Yawn, B.P., Ebbert, J.O., Roger, V.L., et al. (2013) Age and Sex Patterns of Drug Prescribing in a Defined American Population. Mayo Clinic Proceedings, 88, 697-707. 
http://www.mayoclinicproceedings.org/article/S0025-6196(13)00357-1/pdf

[6] Attitudes and Beliefs about the Use of Over-the-Counter Medicines: A Dose of Reality. National Council on Patient Information and Education; c2002.

http://www.bemedwise.org/documents/final_survey.pdf 


\section{Appendix 1}

Demographic Information

What is your age?

- $18-25$

- $26-30$

- $31-35$

- $36-40$

- $41-45$

- $46-50$

- $51-55$

- $56-60$

- $61-65$

- $65+$

What is your gender?

- Male

- Female

- Prefer not to answer

What is your highest level of education?

- Did not complete high school

- High School/GED

- Some college

- Associate's Degree/Trade school

- Bachelor's Degree

- Master's Degree

- Advanced Graduate degree of Ph.D.

How many miles per week do you run on average?

- 0 - 5 miles

- 6 - 10 miles

- 11 - 15 miles

- 16 - 20 miles

- 21 - 25 miles

- 26 - 30 miles

- 31 - 35 miles

- 36 - 40 miles

- $40+$ miles

Do you take any prescription medications on a daily basis for a chronic condition (e.g., diabetes, high blood pressure, etc.)?

a. Yes

b. No

Have you ever taken an OTC medication before a run as a preventative measure? (e.g., Ibuprofen before a run to prevent pain or Imodium before a run to prevent a bowel movement)
a. Yes
b. No 


\section{OTC Usage Questions}

For the following situation, pick the choice that best describes you:

1) You been having symptoms of a cold for a few days (congestion, runny nose, etc.) which has been bothersome. To best relieve your symptoms, your first option is to:

a. Drink plenty of fluids and/or rest

b. Take an herbal supplement or vitamin

c. Take an over-the-counter (OTC) cold medication

d. Exercise

2) After a long day at work, you start to get a headache. Select the option that you would choose first to help relieve your headache.

a. Rest

b. Take an herbal supplement or vitamin

c. Take an OTC pain medication

d. Exercise

3) You ate some food last night that upset your stomach and you have had some diarrhea. Select the option that you would choose first to help relieve your diarrhea.

a. Drink plenty of water or Gatorade

b. Take an herbal supplement or vitamin

c. Take an OTC medication for diarrhea

d. Exercise

4) A spicy meal gave you some heartburn that has woken you up from sleep. Select the option that you would choose first to help you relieve your heartburn.

a. Drink water or milk

b. Take an herbal supplement or vitamin

c. Take an OTC medication for heartburn

d. Sleep sitting up or at an angle

5) Your most recent long run has left you with sore muscles. Select the option that you would choose first to help relieve your pain.

a. Rest and ice

b. Take an herbal supplement or vitamin

c. Take an OTC pain medication or pain relief cream

d. Stretch, massage, or roll out your muscles

6) When/if you take OTC pain medication for minor aches and pains associated with running, what medication do you prefer?
a. Aspirin
b. Tylenol (acetaminophen)
c. Aleve (naproxen)
d. Motrin (ibuprofen)

7) Have you visited any of the following for relief of ailments or pain associated with running? Choose all that apply. 

a. Chiropractor
b. Sports medicine doctor
c. Massage therapist
d. Acupuncturist
e. Podiatrist

Submit or recommend next manuscript to SCIRP and we will provide best service for you:

Accepting pre-submission inquiries through Email, Facebook, LinkedIn, Twitter, etc. A wide selection of journals (inclusive of 9 subjects, more than 200 journals)

Providing 24-hour high-quality service

User-friendly online submission system

Fair and swift peer-review system

Efficient typesetting and proofreading procedure

Display of the result of downloads and visits, as well as the number of cited articles

Maximum dissemination of your research work

Submit your manuscript at: http://papersubmission.scirp.org/

Or contactpp@scirp.org 